\title{
Climate and carbon-cycle variability over the last millennium
}

\author{
J. H. Jungclaus ${ }^{1}$, S. J. Lorenz ${ }^{1}$, C. Timmreck ${ }^{1}$, C. H. Reick ${ }^{1}$, V. Brovkin ${ }^{1}$, K. Six ${ }^{1}$, J. Segschneider ${ }^{1}$, M. A. Giorgetta ${ }^{1}$, \\ T. J. Crowley ${ }^{2}$, J. Pongratz ${ }^{1, *}$, N. A. Krivova ${ }^{3}$, L. E. Vieira ${ }^{3, *}$, S. K. Solanki ${ }^{3,4}$, D. Klocke ${ }^{1}$, M. Botzet ${ }^{1}$, M. Esch ${ }^{1}$, \\ V. Gayler ${ }^{1}$, H. Haak ${ }^{1}$, T. J. Raddatz ${ }^{1}$, E. Roeckner ${ }^{1}$, R. Schnur ${ }^{1}$, H. Widmann ${ }^{1}$, M. Claussen ${ }^{1,5}$, B. Stevens ${ }^{1,6}$, and \\ J. Marotzke ${ }^{1}$ \\ ${ }^{1}$ Max Planck Institute for Meteorology, Bundesstrasse 53, 20146 Hamburg, Germany \\ ${ }^{2}$ School of Geosciences, University of Edinburgh, West Mains Road, Edinburgh EH9 3JW, UK \\ ${ }^{3}$ Max Planck Institute for Solar System Research, Max Planck Strasse 2, 37191 Katlenburg-Lindau, Germany \\ ${ }^{4}$ School of Space Research, Kyung Hee University, Gyeonggi 466-701, Yongin, Korea \\ ${ }^{5}$ KlimaCampus, University of Hamburg, Bundesstrasse 55, 20146 Hamburg, Germany \\ ${ }^{6}$ Department of Atmospheric and Oceanic Sciences, University of California Los Angeles, Los Angeles, CA 90095, USA \\ *now at: Department of Global Ecology, Carnegie Institution of Washington, 260 Panama St., Stanford, CA 94305, USA \\ ***now at: Laboratoire de Physique et Chemie de l'Environment et de l'Espace, CNRS \& University of Orleans, \\ 3A Av. De la Recherche Scientifique, 45071 Orléans, France
}

Received: 4 May 2010 - Published in Clim. Past Discuss.: 26 May 2010

Revised: 8 October 2010 - Accepted: 11 October 2010 - Published: 26 October 2010

\begin{abstract}
A long-standing task in climate research has been to distinguish between anthropogenic climate change and natural climate variability. A prerequisite for fulfilling this task is the understanding of the relative roles of external drivers and internal variability of climate and the carbon cycle. Here, we present the first ensemble simulations over the last 1200 years with a comprehensive Earth system model including a fully interactive carbon cycle. Applying up-to-date reconstructions of external forcing including the recent lowamplitude estimates of solar variations, the ensemble simulations reproduce temperature evolutions consistent with the range of reconstructions. The 20th-century warming trend stands out against all pre-industrial trends within the ensemble. Volcanic eruptions are necessary to explain variations in pre-industrial climate such as the Little Ice Age; yet only the strongest, repeated eruptions lead to cooling trends that differ significantly from the internal variability across all ensemble members. The simulated atmospheric $\mathrm{CO}_{2}$ concentrations exhibit a stable carbon cycle over the pre-industrial era with multi-centennial variations somewhat smaller than in the observational records. Early land-cover changes have modulated atmospheric $\mathrm{CO}_{2}$ concentrations only slightly. We provide a model-based quantification of the sensitivity (termed $\gamma$ ) of the global carbon cycle to temperature for a variety of climate and forcing conditions. We diagnose a dis-
\end{abstract}

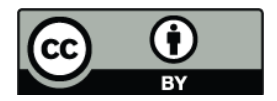

Correspondence to: J. H. Jungclaus (johann.jungclaus@zmaw.de) tinct dependence of $\gamma$ on the forcing strength and time-scales involved, thus providing a possible explanation for the systematic difference in the observational estimates for different segments of the last millennium.

\section{Introduction}

Northern Hemisphere (NH) temperature reconstructions (Jansen et al., 2007; Mann et al., 2008; Mann et al., 2009) for the last millennium differ substantially among each other, raising questions (Trouet et al., 2009; Mann et al., 2009) about the spatial and temporal extent of climatic epochs such as the Medieval Warm Period (MWP, ca. 900-1250 AD) and the Little Ice Age (LIA, ca. 1500-1850 AD). The large heterogeneity in space and time has also lead several authors to prefer the expression Medieval Climate Anomaly (MCA, e.g., Mann et al., 2009). Climate models' ability to reproduce the observed records can help understand the mechanisms behind the climate variability of the last millennium and provides context for current and future climate change. Alternatively, discrepancies between models and observations can help identify gaps in our understanding, or possible inaccuracies in the observational record. A model system that simulates both the carbon-cycle and the spatially resolved internal climate variability allows us to exploit the fullness of the observational record in order to quantify both the forced response of the system and the carbon-cycle climate feedback

Published by Copernicus Publications on behalf of the European Geosciences Union. 
over a variety of periods and boundary conditions. However, to assess internal variability, it is essential to perform ensemble integrations in a manner that begins to spatially resolve the dynamics of the climate system. Here, we present the first such simulations for the last millennium, with a comprehensive Earth System Model (ESM) including a fully interactive carbon cycle. This is a significant advance over previous efforts, which have been restricted to Energy Balance Models (Crowley, 2000) and ESMs of Intermediate Complexity (e.g., Gerber et al., 2003; Goosse et al., 2005), to single realisations of coupled models without a carbon cycle (e.g., Gonzáles-Rouco et al., 2003; Ammann et al., 2007, Servonnat et al., 2010), or to simulation that did not span the entire last millennium (Stendel et al., 2006; Tett et al., 2006; Spangehl et al., 2010). The introduction of an interactive carbon cycle is considered to be a major advance in climate modelling (Friedlingstein et al., 2006) but comprehensive climate-carbon cycle models have been applied mostly to the anthropogenic era and to study future changes in the carbon cycle-climate connection (e.g. Raddatz et al., 2007; Fröhlicher et al., 2009; Fröhlicher and Joos, 2010).

In this paper we concentrate on the analysis of the relative role of internal variability and external forcing for shaping $\mathrm{NH}$ temperature and on the evolution of the carbon cycle over the last 1200 years. In Sect. 2, we describe the experimental design, the ESM, and the external forcing datasets. Section 3 presents the results starting with a comparison of simulated and reconstructed NH temperatures (Sect. 3.1), followed by an assessment of trends in forced and unforced simulations (Sect. 3.2 and Sect. 3.3). In Sect. 3.4 we discuss the simulated $\mathrm{CO}_{2}$ evolution in the forced experiments and (Sect. 3.5) assess the sensitivity of the carbon cycle to temperature changes.

\section{Model and experimental design}

The experimental strategy is briefly described as follows. After a multi-century spin-up phase in which the carbon cycle was brought into equilibrium, we ran a 3000-year unforced control experiment under $800 \mathrm{AD}$ orbital conditions and preindustrial greenhouse gas concentrations. Starting from different ocean initial conditions we performed a five-member ensemble (E1) with the standard external forcing set spanning the time $800 \mathrm{AD}$ to $2005 \mathrm{AD}$. In order to account for uncertainty in the solar forcing we ran a second three-member ensemble (E2) with an alternative reconstruction of solar irradiance (see below). In addition, we have performed sensitivity experiments with just one external forcing at a time.

\subsection{The Earth System Model}

We have used the Max Planck Institute for Meteorology Earth System Model (MPI-ESM) consisting of the general circulation models for the atmosphere ECHAM5 (Roeck- ner et al., 2003) and for the ocean MPIOM (Marsland et al., 2003). ECHAM5 is run at T31 resolution $\left(3.75^{\circ}\right)$ with 19 vertical levels, resolving the atmosphere up to $10 \mathrm{hPa}$. MPIOM applies a conformal mapping grid with a horizontal resolution ranging from $22 \mathrm{~km}$ to $350 \mathrm{~km}$. This grid set-up is a low-resolution version of the model used for the scenario simulations (Jungclaus et al., 2006) for the Intergovernmental Panel of Climate Change (IPCC) and the Coupled Carbon Cycle Climate Modelling Intercomparison Project (C4MIP, Friedlingstein et al., 2006) simulations. The ocean model includes a thermodynamic-dynamic sea-ice model with viscous-plastic rheology (Hibler, 1979) and considers also snow on sea ice. Surface albedo on land is also affected by a time-varying snow cover (Roeckner et al., 2003), but a variable glacier mask or land-ice model is not included. Ocean and atmosphere are coupled daily without flux corrections using the OASIS3 coupler (Valcke et al., 2003). The carbon cycle model comprises the ocean biogeochemistry module HAMOCC5 (Wetzel et al., 2006) and the land surface scheme JSBACH (Raddatz et al., 2007). Threedimensional transport of carbon within the ocean and the atmosphere as well as the exchange between atmosphere and land biosphere are calculated each time step so that the daily and seasonal cycle of the atmospheric $\mathrm{CO}_{2}$ concentrations are resolved. The carbon flux between the ocean and the atmosphere is determined daily at each coupling time step.

\subsection{External forcing}

\subsubsection{Solar forcing}

Variations in Total Solar Irradiance (TSI) over the last centuries have recently been argued to be much smaller than previously thought (Wang et al., 2005; Krivova et al., 2007, Gray et al., 2010). Therefore, the TSI forcing used as our standard forcing exhibits a total increase of $0.1 \%$ $\left(\sim 1.3 \mathrm{Wm}^{-2}\right)$ from the Maunder Minimum (1647-1715 AD) to today, which is in agreement with other recent evaluations (Steinhilber et al., 2009; Tapping et al., 2007). The data set has daily sampling from 1627 AD onward (Krivova et al., 2007; Balmaceda et al., 2007). In this period, the 11-year activity cycle is included since solar irradiance was reconstructed from historical records of sunspot numbers. Prior to the Maunder Minimum, no direct estimates of solar variability, such as sunspot observations, are available. The TSI time series for the period $800 \mathrm{AD}$ to the Maunder Minimum is reconstructed from estimates of the solar open magnetic flux based on cosmogenic isotope ${ }^{14} \mathrm{C}$ concentrations in tree rings (Solanki et al., 2004; Krivova and Solanki, 2008; Usoskin et al., 2007). In order to derive a consistent time series applied as solar forcing for the model, an 11-year cycle has been artificially superimposed prior to the Maunder Minimum. The amplitude was estimated from the analysis of the relationship between the cycle amplitude and overall solar activity, as represented by the 11-year running mean of the 
TSI between $1700 \mathrm{AD}$ and present. To account for uncertainty in the amplitude in solar forcing and to enable comparison with earlier model studies (Gonzáles-Rouco et al., 2003; Ammann et al., 2007), we ran a second ensemble (E2) of three simulations with considerably stronger MaunderMinimum-reduction. The TSI series used for the E2 ensemble is based on another compilation of ${ }^{14} \mathrm{C}$ and ${ }^{10} \mathrm{Be}$ production rates (Bard et al., 2000) from which an annual data set was derived (Ammann et al., 2007). The E2 solar forcing exhibits roughly $3.5 \mathrm{Wm}^{-2}(0.25 \%)$ change from the Maunder Minimum to the modern period (1950-2000 AD). In contrast to the E1 forcing, the data set of Amman et al. (2007) does not include an 11-year cycle. Both TSI forcing series are applied as anomalies w.r.t. the solar constant value of $1367 \mathrm{Wm}^{-2}$ that is used in the control run for the coupled model.

\subsubsection{Volcanic forcing}

The volcanic effect on radiation is calculated online in the model using time series of aerosol optical depth (AOD) at $0.55 \mu \mathrm{m}$ and of the effective radius ( $\left.R_{\text {eff }}\right)$ (Crowley et al., 2008). The time resolution of the series is ten days and the data are provided at four equal-area latitude bands. AOD estimates are based on a correlation between sulphate in Antarctic ice cores and satellite AOD data from the 1991 eruptions of Mt. Pinatubo and Cerro Hudson (Sato et al., $1993)$. $R_{\text {eff }}$ growth and decay is based on satellite observations of the Pinatubo eruption in 1991, and on estimated particle sizes of very large eruptions by microphysical simulations (Pinto et al., 1989). In the model AOD is distributed between $20-86 \mathrm{hPa}$ over three vertical levels, with a maximum at $50 \mathrm{hPa}$. Extinction, single scattering albedo and the asymmetry factor are calculated online for the six solar bands $(0.185-4 \mu \mathrm{m})$ of the ECHAM5 radiation scheme and extinction for the 16 long-wave wavelength bands (3.3$100 \mu \mathrm{m})$ from the time dependent AOD, $R_{\text {eff }}$ and normalized optical parameters. The normalized parameters are calculated for all wavelength bands dependent on an assumed lognormal aerosol size distribution with an effective radius between 0.02 and $1 \mu \mathrm{m}$ and a constant standard deviation of $1.8 \log$ units.

Sensitivity experiments for the largest eruption of the last millennium (1258 AD) demonstrate that $R_{\text {eff }}$ variations matter and that aerosol particle sizes substantially larger than those observed after Pinatubo yield temperature changes consistent with reconstructions (Timmreck et al., 2009; and references therein).

\subsubsection{Land cover changes}

Anthropogenic land cover change is considered by applying a reconstruction of global agricultural areas and land cover (Pongratz et al., 2008). The global maps with a spatial resolution of $0.5^{\circ}$ and an annual timescale contain 14 vege- tation types and discriminate between the agricultural categories cropland, and $\mathrm{C} 3$ and $\mathrm{C} 4$ pastures. The reconstruction merges published maps of agriculture from 1700 to $1992 \mathrm{AD}$ and a population-based approach to quantify agriculture from AD 800 to 1700. This approach captures the general expansion of agriculture but also abandonment of agricultural areas and subsequent re-growth of natural vegetation due to regionally confined historical events, such as warfare and epidemics (Pongratz et al., 2009).

\subsubsection{Orbital forcing}

The ECHAM5 model contains a representation of periodic changes of the Earth's orbit around the Sun on all frequencies, including short term variations. It uses the Variation Seculaires des Orbites Planetaires (VSOP) analytical solution (Bretagnon and Francou, 1988) and determines today's orbit for an interval -4000 to 8000 years with respect to the year 2000 accurately. Additionally, the nutation, a small wobble of the Earth's rotational axis with a period of 18.6 years, is accounted for in the model.

\subsubsection{Greenhouse gas forcing}

The $\mathrm{CO}_{2}$ concentration is calculated interactively within the model. Fossil fuel emissions for the historical period are prescribed after Marland et al. (2003). The concentrations of the next two major greenhouse gases, methane $\left(\mathrm{CH}_{4}\right)$ and nitrous oxide $\left(\mathrm{N}_{2} \mathrm{O}\right)$ follow MacFarling Meure et al. (2006). The data sets are applied to the model using annual resolution, where a simple spline function is used for interpolating the data. For all simulations, present day ozone climatology (Fortuin and Kelder, 1998) is prescribed.

\subsubsection{Aerosol forcing}

The climatology of the background aerosol distribution (Tanre et al., 1984) distinguishes time independent spatial distributions of tropospheric and stratospheric background aerosols. The aerosols are described by a maximum AOD at $0.55 \mu \mathrm{m}$, normalized horizontal distributions, normalized vertical integrals, and a troposphere-stratosphere discrimination factor. The AOD at $0.55 \mu \mathrm{m}$ is rescaled to the spectral intervals of the ECHAM radiation scheme. The natural and anthropogenic sulphate dry mass are provided as monthly means in $\mu \mathrm{gSO}_{4}^{2-} \mathrm{m}^{-3}$ and converted online to optical parameters. The data were interpolated linearly between 1750 (i.e. natural pre-industrial distribution) and 1850 and the 1850 to 1980 sulphate fields are based on historical reconstructions (Lefohn et al., 1999), but have been rescaled to the 1990 SRES scenario to avoid any discontinuities with the SRES scenario which is used for the time 1980-2005 (see Boucher and Pham, 2002). 


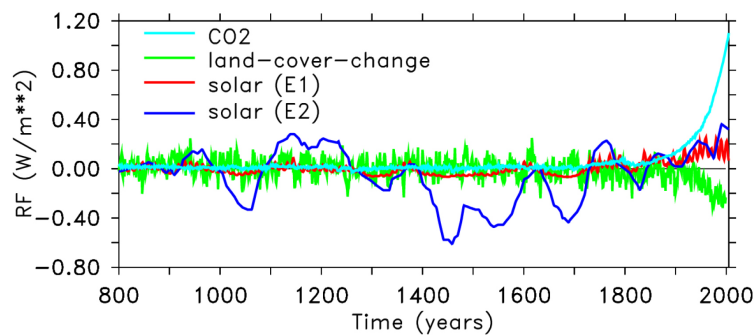

a)

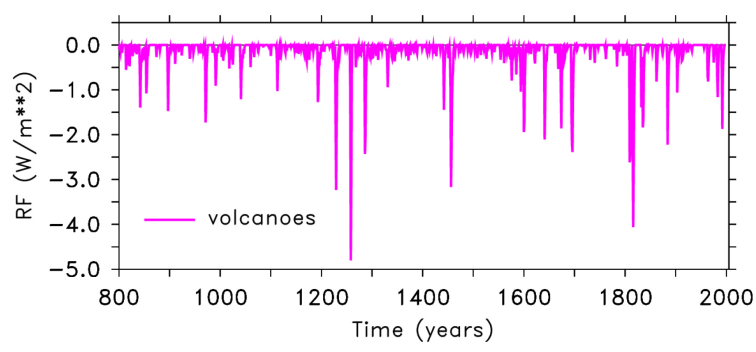

b)

Fig. 1. Radiative forcing at the top of the atmosphere displayed as annual means (a) for the greenhouse-gas forcing $\left(\mathrm{CO}_{2}\right)$, land-coverchange (albedo effect only), and solar forcing, and (b) for volcanic forcing displayed with a different axis. Anomalies from solar irradiance and $\mathrm{CO}_{2}$ variations are calculated w.r.t. their pre-industrial control mean ( $1367 \mathrm{Wm}^{-2}$ and $280.02 \mathrm{ppm}$, respectively). The radiative forcing from volcanic aerosol injections and land-coverchanges are calculated from dedicated experiments with one single forcing component.

\subsubsection{Radiative forcing from the external drivers}

Effective radiative forcings (Fig. 1a, b) are calculated off-line with the ECHAM5 isolated radiative transfer code following the Wetherald and Manabe (1998) approach for calculating radiative feedbacks. The radiative forcing at the top of the atmosphere is defined as the change in radiative fluxes at the top of the atmosphere due to the change in one single variable $x$. All other variables are taken from one reference year and do not change from year to year. The forcings defined here are all instantaneous and do not allow any atmospheric adjustment. For $\mathrm{CO}_{2}$ concentration, the forcing is calculated in bins of $\mathrm{CO}_{2}$ changes with respect to the average $\mathrm{CO}_{2}$ concentrations of the control run $(280.08 \mathrm{ppm})$. Land-cover-change related radiative forcing reflects only the effect of changing surface albedo and is calculated relative to the period from 800 to 850 from the experiment with landcover-changes as the only forcing. Volcanic forcing introduces the strongest disturbances in terms of amplitude, but these are short-lived events. If the volcanic forcing time series was smoothed by, say a 30-year running mean, the amplitude would be of similar magnitude as the other forcings. However, the volcanic forcing is, in fact, concentrated in individual years rather than spread out over decades to centuries.

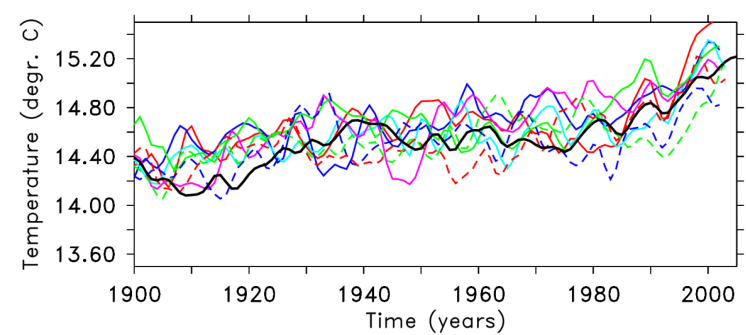

a)

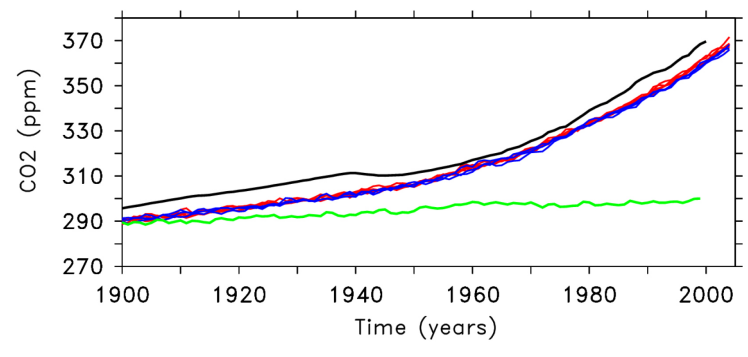

b)

Fig. 2. $\mathrm{NH}$ temperature and global $\mathrm{CO}_{2}$ concentration in the 20th century. (a) 20th century Northern Hemisphere (land and ocean) $2 \mathrm{~m}$ air temperatures (5-year running means) simulated in ensemble E1 (solid coloured lines) and E2 (dashed coloured lines) in comparison with the HadCRUT3v dataset (black line, obtained from the Climatic Research Unit, http://www.cru.uea.ac.uk/ cru/data/temperature), (b) 20th century global $\mathrm{CO}_{2}$ concentration (yearly data) simulated in ensemble E1 (red) and E2 (blue) in comparison with a combination of ice core data and atmospheric measurements (black) provided by the Paleo Model Intercomparison Project at http://pmip3.lsce.ipsl.fr. The green line is the respective curve for the land-cover-change-only experiment.

\section{Evolution of Northern Hemisphere temperature and global $\mathrm{CO}_{2}$ concentration over the last 1200 years}

\subsection{0th century temperature and $\mathrm{CO}_{2}$ evolution}

As a first step we demonstrate the ability of the model to reproduce important aspects of the recent period of global climate change. The simulated $\mathrm{NH}$ temperature evolution over the 20th century agrees well with the instrumental record (Fig. 2a). Both observed and modelled time series exhibit a warming trend of about $0.6^{\circ} \mathrm{C}$ over the 20th century that is superimposed by pronounced multidecadal variability. The two ensembles with different solar forcing do not differ significantly from each other, indicating that greenhouse-gas forcing and internal variability dominate over solar forcing over the last century. Correlations between the ensemble means with the HadCRU data show somewhat higher values (0.79) for the E1 than for the E2 (0.65) ensemble over the 20th century. The E2 ensemble members are slightly colder at the beginning of the industrialized era (see below). Over the 20th century, the E2 solar forcing exhibits stronger variability on the multi-decadal time scale (Fig. 1a), including maxima in the 1940s and 1990s and a minimum in the 1970s. 
The E2 ensemble mean arrives at slightly colder temperature to the end of the simulations than the E1 mean, probably because the lagged response to the solar forcing increase in the 1990s has not fully evolved. Another explanation for differences between the two simulations and the better correlation between E1 and HadCRU could be the absence of the 11-year cycle in the Amman et al. (2007) solar forcing.

The simulated global atmospheric $\mathrm{CO}_{2}$ concentration in the 20th century (Fig. 2b) stays below the observed record (a combination of ice core data and atmospheric measurements provided by the Paleo Model Intercomparison Project at http://pmip3.lsce.ipsl.fr/. By the end of the 20th century, the simulations arrive at $10 \mathrm{ppm}$ lower values than the observations. Part of this discrepancy can be explained by the roughly $3 \mathrm{ppm}$ lower $\mathrm{CO}_{2}$ concentration at the very beginning of the experiment ( $800 \mathrm{AD})$. For the industrial period (1850-2000 AD) the simulated carbon content in the atmosphere increases by $163 \mathrm{GtC}$ in the ensemble mean, the land inventory changes by $-3 \mathrm{GtC}$ and the ocean takes up $119 \mathrm{GT}$. The respective numbers given from a combination of reconstructions and model estimates (Houghton, 2007) read $175 \mathrm{Gt} \mathrm{C}, 40 \mathrm{Gt} \mathrm{C}$, and $140 \mathrm{GtC}$. However, terrestrial fluxes in particular (see Table 1 in Houghton, 2007) come with a large range of uncertainty. As has been pointed out by Pongratz et al. (2009) the primary emissions from land-use change simulated by our model are similar to other studies (DeFries et al. 1999; Olofsson and Hickler, 2008), though at the lower end. Therefore we attribute the lower-thanobserved $\mathrm{CO}_{2}$ concentrations in part to an underestimation of land-use change emissions that are not compensated for by a somewhat too weak ocean uptake. In addition, the turnover of soil may be too slow. For the period 1990-2000 AD, however, the simulated carbon sources and sinks for the 1990s are well in the range of observations: atmospheric growth is $3.2 \mathrm{GtC}$ in the simulations vs. $3.1 \mathrm{GtC}$ in the observations. The ocean sink is $2.1(2.2) \mathrm{GtC}$, the land-atmosphere net flux is 1 (1) Gt C and the land use emissions account for 1.3 (1.6) GtC (numbers in brackets from Le Quéré et al., 2009). Overall, the differences between simulated and observed $\mathrm{CO}_{2}$ concentration at the beginning of the 21 st century are well in the range of state-of-the-art climate carbon models, such as those carried out in the framework of C4MIP (Friedlingstein et al., 2006; Raddatz et al., 2007). The $\mathrm{CO}_{2}$ increase from land-cover changes is moderate compared to contribution from fossil-fuel emissions. Over the last millennium, land-cover changes contribute roughly $20 \mathrm{ppm}$ (Pongratz et al., 2009).

\subsection{Northern Hemisphere temperature changes over the last 1200 years}

Over time-intervals from decades to centuries, simulated $\mathrm{NH}$ temperatures (Fig. 3a) from all ensemble members differ significantly from the range of internal variability defined by the control experiment. Strong volcanic eruptions, particu-

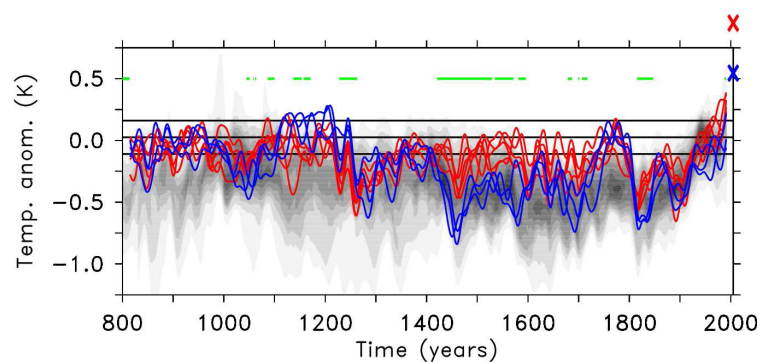

a)

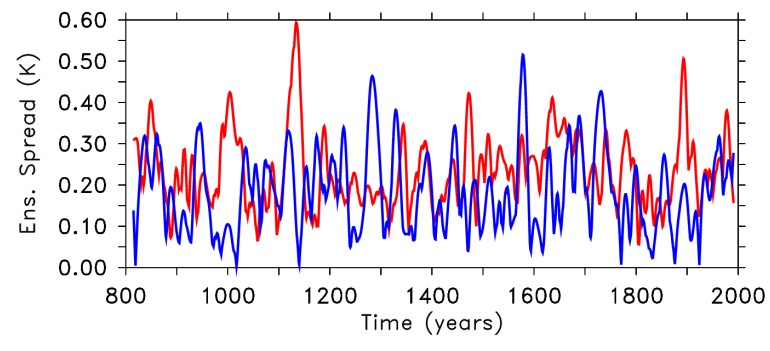

b)

Fig. 3. Evolution of simulated temperature over the last 1200 years: (a) Northern Hemisphere $2 \mathrm{~m}$ land temperature anomalies w.r.t. the 1961-1990 mean for ensembles E1 (red) and E2 (blue) in comparison with the range of reconstructions (gray scale, redrawn from Jansen et al., 2007, see Appendix A). Black horizontal lines indicate the control experiment mean and its 5th-95th percentile range. Green horizontal bars indicate periods where the ensembles do not overlap with each other. Time series are smoothed by a 31-yr running mean. Crosses at the right axis denote the ensemble means (annual average) at the end of the simulation (2005), (b) ensemble spread for the ensembles E1 (red), and E2 (blue).

larly the cumulative effect of several volcanoes around the most severe eruptions in $1258 \mathrm{AD}, 1453 \mathrm{AD}$, and $1815 \mathrm{AD}$, leave a long-lasting imprint on $\mathrm{NH}$ climate. Note that the generally somewhat cooler mean states in the ensembles are a result of the absence of volcanic aerosol forcing in the control run. Modulation by changing solar irradiance is more pronounced in the E2 ensemble where we identify the largest pre-industrial temperature anomalies in the 15th century during a superposition of the $1453 \mathrm{AD}$ Kuwae eruption and the Spörer-Minimum (1450-1550 AD) in TSI. Overall, the simulations show the warmest pre-industrial $\mathrm{NH}$ temperatures around $1050-1250 \mathrm{AD}$ and in the late 18th century while cold anomalies prevail during the 13th, 15th, 17th and early 19th centuries. In contrast to the E1 experiments, the E2 ensemble exhibits a notable MWP that is associated with the peak in the solar forcing in the 12th century (Fig. 1a). While the world-wide distributed data compiled by Bradley et al. (2003) showed their warmest 30-year period anywhere between 1000 and 1200, most NH temperature reconstructions (Jansen et al., 2007; Mann et al., 2008; Mann et al., 2009) indicate a MWP centred on the turn of the millennium and decreasing temperatures from 1150 onwards. In the simulations strong cooling sets in only after the $1258 \mathrm{AD}$ 
volcanic eruption. From the 15th to the mid-18th century, the two ensembles do not overlap and the ensemble mean of the E2 simulations agrees somewhat better with the consensus of reconstructions. However, there is considerable variation within the ensembles. The ensemble spreads (Fig. 3b) are of similar magnitude as the control run's range of internal variability, indicating that they provide an adequate representation of internal variability even though the ensemble size is small. The magnitude of the ensemble spreads is, however, considerable when compared to the multi-centennial temperature changes. In particular, the E1 ensemble exhibits spread of $0.25-0.3 \mathrm{~K}$ almost continuously between 1450 and 1700 AD. During the first part of the 17th century, where the reconstructions show the coldest part of the LIA (Frank et al., 2010), a "cold" E1 realization gives a negative temperature anomaly nearly as strong as the much more strongly forced E2 simulations. Therefore, multi-century climate variations such as the MWP-LIA transition may not require particular strong solar forcing but can be attributed, at least in parts, to internal variability on centennial time-scales. Trouet et al. (2009) interpret the warm MWP conditions over Europe and North America as expression of a positive North Atlantic Oscillation (NAO)/Arctic Oscillation (AO) anomaly that results from a dynamical response to the solar forcing anomaly and occurs sustained over several centuries. In our simulations, we cannot identify such a long-term response of atmospheric regimes to the external forcing. Mann et al. (2009) compare two general circulation model simulations, one of them including a well-resolved stratosphere and the effects of ozone photochemistry (based on the model of Shindell et al., 2001). They find that only the latter reproduces the observed pattern of enhanced North-American, North Atlantic, and Arctic-Eurasian warming as a result of a positive $\mathrm{NAO} / \mathrm{AO}$ response. While it must be stated that other models with resolved stratospheric dynamics and ozone chemistry do not show the same projection onto the leading atmospheric modes (e.g., the UK Unified Model, Palmer et al., 2004) it is possible that our model does not adequately represent complex interactions between variability modes, such as NAO and El-Niño-Southern Oscillation (ENSO).

Another way of characterizing the MWP-LIA overall cooling was proposed by Frank et al. (2010) who compare the warmest 30-year climatic period during the MWP epoch with the coldest 30-year period during the time of the LIA. According to their probabilistic analysis, which involved recalibrating nine different reconstructions, the best estimate for the difference between the coldest episode of the LIA (1601-1630) and the warmest pre-industrial period (1071$1100)$ is $0.38 \mathrm{~K}$. The ensemble means of both our ensemble simulations indicate common warm eras in the 11th to the mid-13th century and the coldest epoch before the onset of anthropogenic warming in the 17th century. The MWP-LIA temperature change defined in this way is then calculated for each ensemble member and for different choices of regional and seasonal averages. The latter were motivated by the data

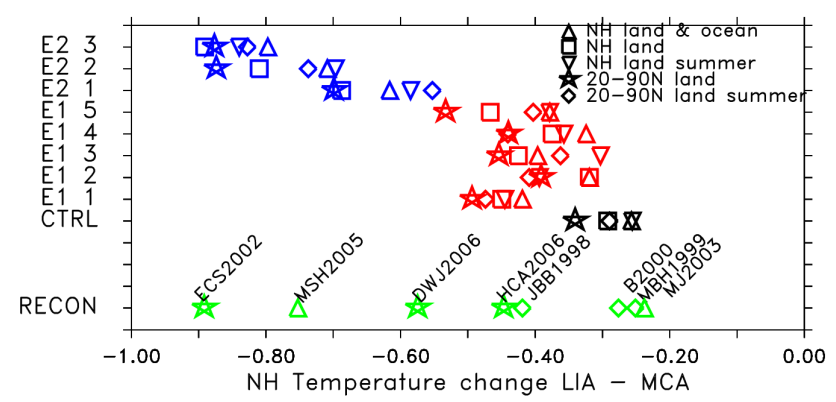

Fig. 4. Northern Hemisphere temperature difference between the coldest 30 year period during the LIA (1550-1750) and the warmest 30 year period during the MWP (900-1300) from the ensembles E1 (red) and E2 (blue), respectively, and the reconstruction data available from Jansen et al. (2007) (green). As an estimate for internal variability, black symbols denote the 5th-95th percentile range of the respective 30-year means from the 3000-year control experiment. Symbols denote different choices of regional and temporal averaging as motivated by the available reconstructions. Acronyms refer to those used in Jansen et al. (2007) (see Appendix A).

available from IPCC (see Jansen et al., 2007, their Table 6.1). The simulated data in Fig. 4 indicate that the choice of season and the selection of land-only or land-and-ocean data points can explain differences of up to $0.2 \mathrm{~K}$ where the $20^{\circ}-90^{\circ} \mathrm{N}$ land data show the strongest response in most simulations. We note that the much larger spread seen in the reconstructions (here not re-calibrated as in Frank et al., 2010) cannot be explained by these choices alone. In the individual simulations, the warmest MWP climatic periods occur between the end of the 11th century and the middle of the 12th century (see Appendix A, Table A1) while the reconstructions suggest a slightly earlier temperature maximum. All experiments and the reconstructions have their coldest LIA period between $1580 \mathrm{AD}$ and $1699 \mathrm{AD}$. The simulations show a certain ensemble spread as a result of internal variability but the E1 experiments cluster around a $0.4 \mathrm{~K}$ cooling whereas the E2 temperature difference is considerably larger. Regarding the Frank et al. (2010) recalibration as one of the best estimates of $\mathrm{NH}$ temperature evolution presently available would suggest that simulations with weak solar forcing yield a MWP-LIA cooling that is more consistent with the reconstruction-based estimate. The simulated response to solar variations certainly depends, however, on the climate sensitivity and can thus be model-dependent. Recent assessments of the global temperature change per $\mathrm{Wm}^{-2}$ (TSI) (Camp and Tung, 2007; Lean and Rind, 2008) arrive at sensitivities between 0.1 and $0.2 \mathrm{~K} /\left(\mathrm{Wm}^{-2}\right)$. Tung et al. (2008) use multiple temperature data sets including reanalysis and in situ data for the last 60 years and determine the response to the 11 -year solar cycle variations to be $0.12-0.17 \mathrm{~K} /\left(\mathrm{Wm}^{-2}\right)$. We carried out a regression analysis for the temperature response in the experiment where the (weak) solar variations represent the only external forcing. For the last 60 years 
we find a sensitivity of $0.15 \mathrm{~K} /\left(\mathrm{Wm}^{-2}\right)$ as response to the 11-year cycle. A respective analysis of low-passed-filtered data over the entire millennium gave somewhat weaker response $\left(0.1 \mathrm{~K} / \mathrm{Wm}^{-2}\right)$ and a longer time-lag. The details of the mechanisms involved in the response at different time scales are presently subject of ongoing analysis. Based on recent findings of Servonnat et al. (2010), low frequency modulations in the forcing invoke, for example, long-lasting responses in the ocean circulation which could explain different sensitivities at different time scales. Nevertheless, the model's sensitivity is well in the range of observational estimates and it is unlikely that too large a model climate sensitivity is compensating for a weak forcing. Moreover, with a larger sensitivity the model would then agree less well with the 20th century record (Fig. 2a).

\subsection{NH Temperature trends}

The long control experiment and the ensembles of forced experiments allow us to analyze whether decadal to centennial warming and cooling trends in NH-mean temperature fall outside the range of internal variability. To identify periods during the last millennium where the $\mathrm{NH}$ temperatures in the forced simulations leave the range of internal variability, we apply detection methods previously developed for the discrimination between anthropogenic climate change and natural variability (Santer et al., 1995; Baehr et al., 2008). In a first step, NH temperatures from the control run are sampled for a specific segment length (Santer et al., 1995) estimating linear trends for 2900 years. For a given length of the estimation period, the probability density function (pdf) derived from the linear trends represents the variability of the unforced system. Following Baehr et al. (2008), the procedure is repeated for segment lengths between 10 and 100 years to derive upper and lower confidence limits for each segment length. Thereafter, linear trends derived throughout the experiments are compared with the confidence limits for the respective segment lengths (see Appendix B). For certain periods, trends over segment lengths between ten and 100 years are significantly different from those based on internal variability, with a random probability of occurrence of less than 0.05. In Fig. 5 these periods are indicated by colour shading where the respective depth of the shading indicates the number of ensemble members that show a significant warming (red) or cooling (blue) at the same time. In other words, the darkest shades of red or blue, respectively, indicate that all ensemble members show a statistically significant deviation from the control experiment. Only the 20th century global warming and the strongest volcanic eruptions leave an imprint of, respectively warming and cooling trends throughout all eight experiments and over all timescales from a few years to a century. Clearly, the stronger solar variability in the E2 ensemble leads to several more significant warming and cooling trends across the entire ensemble. On the other hand, light shadings in Fig. 5 a indicate periods (including
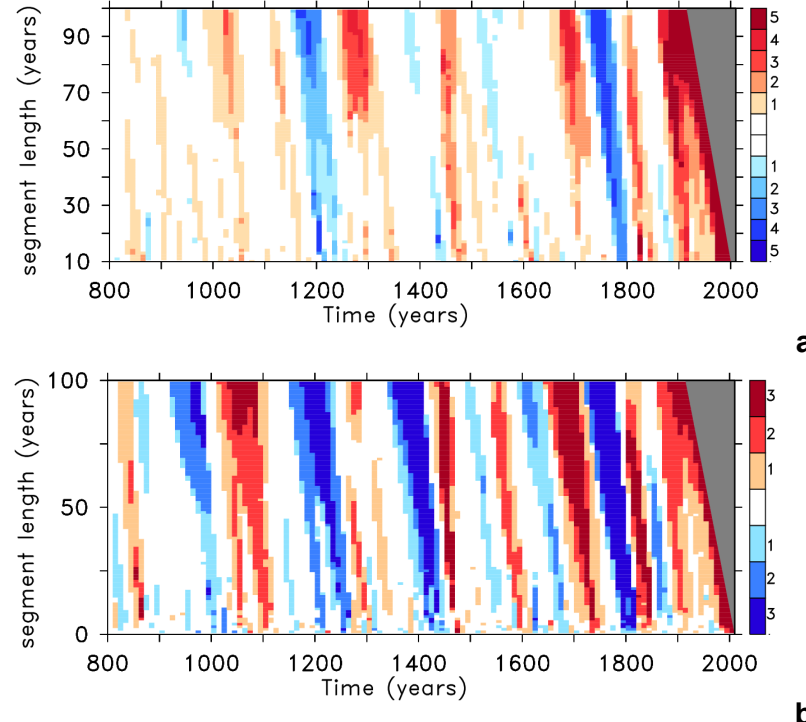

a)

b)

Fig. 5. Analysis of trends in the full-forcing experiments in the ensembles E1 (a) and E2 (b). The analysis identifies periods during which warming (shades of red) and cooling (shades of blue) trends (starting dates at the x-axis) exceed the 5th-95th percentile range of the respective trends in the control experiment. The intensity of the colour denotes the number of ensemble members showing the same behaviour so that, for example, the darkest shade of red indicates that all ensemble members show warming trends significantly different from the control run.

parts of the MWP and LIA) in E1 where internal variability plays a larger role. To draw any conclusion, which of the ensembles give a more realistic representation would, however, require a careful analysis of the observed data sets, which is beyond the scope of this paper.

\subsection{Evolution of atmospheric $\mathrm{CO}_{2}$ over the last 1200 years}

Pre-industrial $\mathrm{CO}_{2}$ variations during the last millennium are small in comparison with glacial-cycle changes, but ice-core records indicate a long-term decline from medieval times to the LIA with considerable difference among various sites. Most notable in the reconstructions (MacFarling Meure et al., 2006; Siegenthaler et al., 2005) is a period of relatively low $\mathrm{CO}_{2}$ concentration that lasted from the late 16th to the mid 18th century, during which time the Law Dome data set indicates a pronounced drop by about $8 \mathrm{ppm}$. It has been hypothesized that land cover changes in the aftermath of warfare and epidemics (Ruddiman, 2007) have caused natural vegetation re-growth and $\mathrm{CO}_{2}$ sequestration on decadal to centennial time scales. Other studies (Joos et al., 1999; Trudinger et al., 2002) deny an active role of anthropogenic $\mathrm{CO}_{2}$ in shaping the LIA climate but argue that the $\mathrm{CO}_{2}$ drop around $1600 \mathrm{AD}$ was a response of the terrestrial biosphere and the oceans to the LIA cooling. Our experiments allow us to explore the two competing hypotheses. 

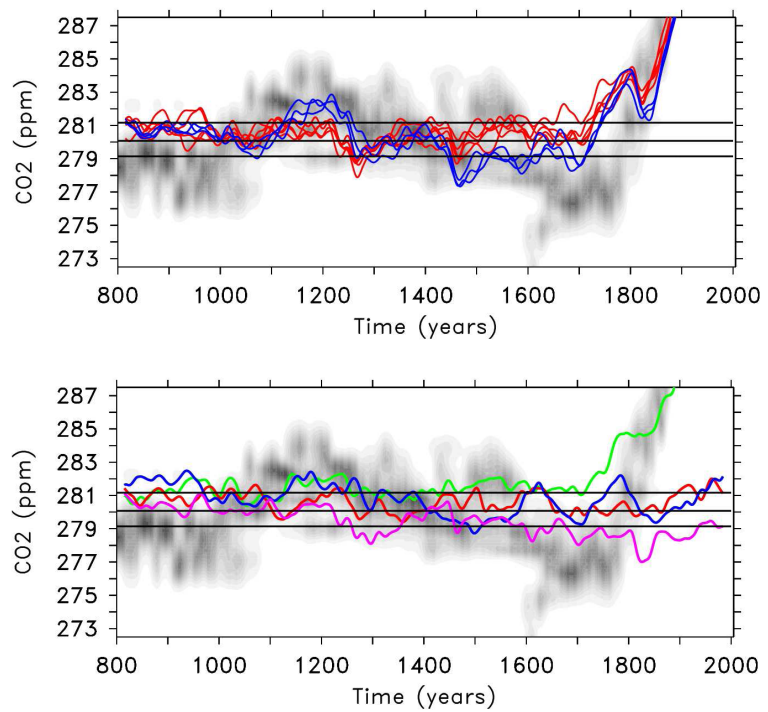

a)

Fig. 6. $\mathrm{CO}_{2}$ concentrations (31-year running mean) from (a) ensembles E1 (red) and E2 (blue) in comparison with a compilation of ice core reconstructions (grey shading, see Appendix A). Black horizontal lines denote the control experiment mean and its 5th95th percentile range, (b) the respective $\mathrm{CO}_{2}$ concentrations from the experiments forced by one single component, i.e. standard solar forcing (red), strong solar forcing (blue), land-cover change (green), and volcanic aerosols (purple).

The simulated land-to-atmosphere carbon fluxes (Fig. 7) indicate that the land biosphere was a source of $\mathrm{CO}_{2}$ throughout most of the millennium, with increasing strength after $1700 \mathrm{AD}$ owing to increasing land-cover changes (Pongratz et al., 2009). The role of the land biosphere as a source was punctuated by brief episodes where it acted as a sink, following volcanic eruptions; carbon uptake then occurred mostly in tropics as a consequence of reduced heterotrophic respiration on land in response to surface cooling (Jones and Cox, 2001). The land biosphere carbon source throughout most of the millennium was partly offset by a consistent ocean uptake, mirroring in strength and timing the land source. After 1950, a rapid decrease in the global deforestation in our landuse-change maps (based on Ramakutty and Foley, 1999) and strong increase in anthropogenic $\mathrm{CO}_{2}$ emission rates lead to a state where $\mathrm{CO}_{2}$-fertilization overcompensated carbon losses from land-use-changes and this turned the land biosphere into a sink (Joos et al., 1999). Therefore, since 1950 both ocean and land have acted as massive carbon sinks, again highlighting the exceptional role of that period.

Both model ensembles exhibit relatively stable $\mathrm{CO}_{2}$ concentrations (Fig. 6a) over the pre-industrial era. During the 20th century, the full forcing runs reproduce the observed increase in atmospheric $\mathrm{CO}_{2}$ similar to other carbon-cycle models (Fig. 2b). The E1 realisations fall below the $\pm 1 \mathrm{ppm}$ 5-95 percentile variability of the control run only after the

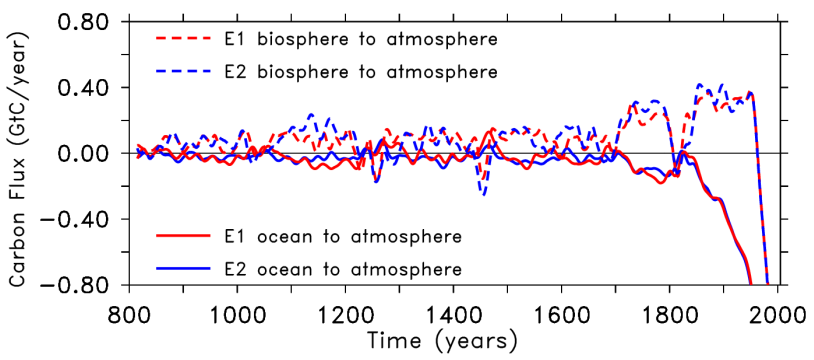

Fig. 7. Carbon fluxes (Gigatons Carbon per year) into the atmosphere for the ensembles E1 (red) and E2 (blue) from the ocean (solid lines) and the land biosphere (dashed lines).

very strong $1258 \mathrm{AD}$ volcanic eruption, and rise above the control run variability only from the early 18th century on. The E2 realisations simulate $\mathrm{CO}_{2}$ significantly high during the MWP and significantly low during the LIA, akin to the $\mathrm{NH}$ temperatures, but none of the simulations reaches the amplitude suggested by the Law Dome data.

Solar radiation changes, land-cover changes, and volcanic eruptions have competing impacts on the carbon budget and on atmospheric $\mathrm{CO}_{2}$ concentration as demonstrated by experiments where just one forcing component was applied (Fig. 6b). Solar forcing modulates atmospheric $\mathrm{CO}_{2}$ as can be most clearly seen in the experiment with the stronger amplitude TSI reconstruction. However, while the E2 ensemble gives generally lower $\mathrm{CO}_{2}$ concentrations throughout the LIA (Fig. 6a), the pronounced drop in the early 17th century can not be associated with solar forcing because both TSI (Fig. 1a) and $\mathrm{CO}_{2}$ (Fig. 6b, dark blue line) records show a positive anomaly around $1610 \mathrm{AD}$. Before $1700 \mathrm{AD}$, land cover changes modulate the $\mathrm{CO}_{2}$ record only by a few ppm, slightly exceeding the range of internal variability. While $\mathrm{CO}_{2}$-sequestration effect as a consequence of vegetation regrowth owing to abandonment of agricultural areas due to warfare and epidemics is discernable in regional and global emissions (Pongratz et al., 2009), it is not sufficient to explain the apparent $\mathrm{CO}_{2}$ decrease during the LIA. On the contrary, after $1500 \mathrm{AD}$, atmospheric $\mathrm{CO}_{2}$ in the land-coverchange-only experiment is almost always higher than the mean of the control experiment. Similar to the solar modulation, cooling by strong and/or cumulative volcanic activity causes changes in the $\mathrm{CO}_{2}$ record of several ppm that last for several decades. Brovkin et al. (2010) study in detail the response of the carbon-cycle to the mid-13th century eruption. The $\mathrm{CO}_{2}$ response in the atmosphere is asymmetric with a fast drop after the eruption and a slow recovery. The $\mathrm{CO}_{2}$ anomaly in the atmosphere lasts typically twice as long as the temperature anomaly itself. They find that the magnitude of the atmospheric $\mathrm{CO}_{2}$ response is primarily determined by the land carbon storage while its duration is set by the marine carbon cycle. The atmospheric carbon loss through cooling by volcanic activity in the 18th to 19th century (Fig. 6b) 
is overcompensated by a massive effect from land-coverchanges. In fact, the strong rise in $\mathrm{CO}_{2}$ levels during the 18th century in the full-forcing experiments (Fig. 6a) can largely be attributed to the increase of emissions from agriculture (green line in Fig. 6b) (see also Reick et al., 2010). Compared to observations, the onset appears to start roughly 50 years too early in the simulations. While the inability of the simulations to reproduce the $\mathrm{CO}_{2}$ decline between 1500 and 1650 cannot be attributed to an overestimation of landuse-change, the emission increase from 1700 onward is one possible reason for the discrepancies between our simulations and the $\mathrm{CO}_{2}$ reconstructions in the 18th century. Uncertainties in the other forcing components must also be considered. The discussion on the magnitude of the solar forcing component has been mentioned earlier but also the detailed representation of volcanic activity (injection height, particle size etc.) could be important. There is a marked imprint of the Tambora (1815) eruption visible in the full-forcing experiments driving the simulated $\mathrm{CO}_{2}$ records to the lower bounds of the observational estimates by 1850 . It is interesting to note that the well-documented cooling after Tambora (the "year without summer") did not leave a marked imprint on the observational $\mathrm{CO}_{2}$ record.

\section{5 $\mathrm{CO}_{2}-$ temperature sensitivity}

Similar to the temperature sensitivity to external forcing that we have discussed with respect to TSI variations, the response of the simulated carbon-cycle to climate variations is certainly model dependent (Friedlingstein et al., 2006; Frank et al., 2010). The processes controlling carbon fluxes between the atmosphere, biosphere, and the oceans are temperature dependent and, on glacial timescales, the sensitivity of the global carbon cycle to temperature is roughly linear with a slope of about $8 \mathrm{ppm} \mathrm{K}^{-1}$ (Woodwell et al., 1998). While empirical estimates based on last-millennium data have reported values up to $40 \mathrm{ppm} \mathrm{K}^{-1}$ (Scheffer et al., 2006; Cox and Jones, 2008), a recent assessment (Frank et al., 2010) quantified $\gamma$ (the sensitivity of atmospheric $\mathrm{CO}_{2}$ to Northern Hemisphere temperature changes) with a median of $7.7 \mathrm{ppm} \mathrm{K}^{-1}$ and a likely range of $1.7-21.4 \mathrm{ppm} \mathrm{K}^{-1}$. For our simulations $\gamma$ falls within this range, though at the lower end (Fig. 8a). Strikingly, however, $\gamma$ is much larger for the forced as compared to the unforced simulations. The regression slopes read $2.7 \mathrm{ppm} \mathrm{K}^{-1}$ for the $\mathrm{E} 1$ ensemble and $4.3 \mathrm{ppm} \mathrm{K}^{-1}$ for the $\mathrm{E} 2$ ensemble, but it is considerably smaller for the control experiment $\left(1.6 \mathrm{ppm} \mathrm{K}^{-1}\right)$. An analysis in the frequency domain (Fig. 8b) reveals increasing sensitivity on longer (centennial to millennial) time-scale. Moreover, running regressions for the ensemble means over the pre-industrial last millennium (Fig. 8c, d) reveal that $\gamma$ is not time-invariant but varies on multidecadal to centennial time-scales. High sensitivities appear at times of pronounced and sustained temperature changes (Figs. 3a, 6a) in response to strong forcing anomalies, such as the vol-
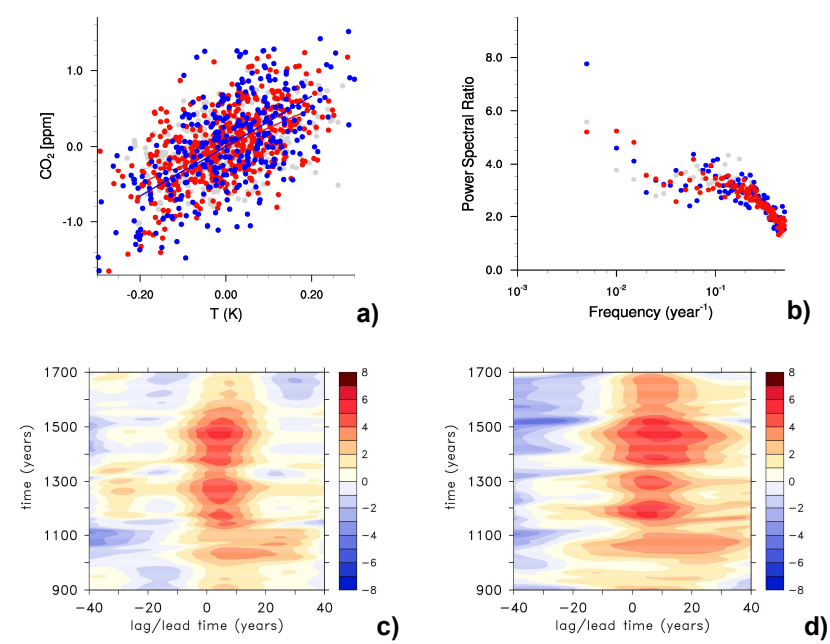

Fig. 8. Climate carbon-cycle sensitivity: (a) Co-variability of annually averaged $\mathrm{NH}$ temperature anomalies with globally and annually averaged $\mathrm{CO}_{2}$ anomalies for the ensemble $\mathrm{E} 1$ (red dots), the ensemble E2 (blue dots) and control (grey dots) experiments. Data points are taken by randomly sampling the low-pass (31-year) filtered data with a mean sample stride of 16 years. Correlations are significant at greater than the $99 \%$ level given an equivalent sample size of 179, 230 and 85 for the control and ensemble E1 and E2 respectively (see Appendix C), (b) Ratio of power spectra as a function of wave-number for the E1 (red) and E2 (blue) ensembles and the control (grey) simulations. In both panels the forced experiments were analyzed for the period between 800 and 1700 , during which time the anthropogenic influence on the carbon cycle was negligible, (c), and (d) running regressions (slopes in $\mathrm{ppm} / \mathrm{K}$ ) between $\mathrm{NH}$ temperature anomalies and globally and annually averaged $\mathrm{CO}_{2}$ anomalies for different time lags (positive lags mean that temperature is leading) for the ensemble means of ensemble E1 (left) and E2 (right). Running regressions were performed over 200-yr windows based on the 31-yr low-passed filtered data.

canic eruptions in the 13th and 14th century where the latter coincides with a maximum solar forcing anomaly (Spoerer Minimum). Both control and forced simulations indicate the strongest response of atmospheric $\mathrm{CO}_{2}$ variations at positive time lags, but the amplitude in the forced run is much higher. Such centennial-scale variations in the sensitivity are apparently also present in the observational record although such estimates should be taken with some care because also the number and quality of the reconstructions changes with time. Frank et al. (2010) found considerable variations for the first (1050-1549 AD: mean $4.3 \mathrm{ppm} \mathrm{K}^{-1}$ ) and second (1550$1800 \mathrm{AD}$ : mean $16.1 \mathrm{ppm} \mathrm{K}^{-1}$ ) half of the pre-industrial period. While our actual numbers for the first period are similar (4.0 and $4.3 \mathrm{ppm} \mathrm{K}^{-1}$ for E1 and E2, respectively; Figs. 8c, d) we do not reproduce the much higher values in the second analysis period reported by Frank et al. (2010) because those include the pronounced $\mathrm{CO}_{2}$ drop around $1600 \mathrm{AD}$ which appears not as pronounced in our simulations. For the period $1550-1700 \mathrm{AD}$ we even get lower 
numbers $\left(2.8\right.$ and $\left.3.9 \mathrm{ppm} \mathrm{K}^{-1}\right)$ than for $1050-1550 \mathrm{AD}$. Nevertheless, the finding that $\gamma$ is not time-invariant and depends on external forcing strength and time-scale is important for the interpretation of the reconstruction-based estimate. The stronger response in the forced simulations may reflect non-linearities in the system, or the different spatiotemporal structure of the temperature patterns in the forced simulations. The detailed processes behind the carbon-cycle response to time-varying forcing are presently analyzed in a subsequent study. Some insight can be gained from the recent study of Brovkin et al. (2010) who, using the same millennium simulations, investigated the impact of a single strong volcanic eruption, i.e. the $1258 \mathrm{AD}$ unknown volcano. They conclude that the $\mathrm{CO}_{2}$ decrease in the atmosphere is explained mainly by reduced heterotrophic respiration on land in response to surface cooling corroborating findings by Jones and Cox (2001). Furthermore, the magnitude of the atmospheric response is determined by the land carbon storage while its duration is set-up by the marine carbon cycle. In particular, the stronger sensitivity at low frequencies (Fig. 8b) suggests that these slow processes associated with carbon storage in the biosphere and oceans determine the feedback strength. Therefore, the slowly varying solar irradiance changes and the cumulative effect of volcanoes that lead to multi-centennial climate variations provide time-scales in which the carbon-cycle response can fully develop.

\section{Discussion and conclusion}

For the first time, ensemble experiments using a comprehensive ESM including a fully-interactive carbon-cycle have been analysed with respect to climate variability and climatecarbon-cycle sensitivity. Applying new reconstructions for the external forcing agents, we are able to quantify the contributions from individual drivers for climate and carbon-cycle response to variations in the forcing. The last millennium with its high-resolution proxies of surface temperatures, volcanic and solar forcing and concomitant $\mathrm{CO}_{2}$ changes challenges our understanding of the climate system. While many of the features of the observed record appear compatible with our simulations and serve to highlight the peculiarity of the present epoch, some mysteries remain. In particular, the magnitude and rate of $\mathrm{CO}_{2}$ change during the LIA and the timing of the MWP prove difficult to reconcile with our best estimates of the climate forcing and response over the last millennium. The $\mathrm{CO}_{2}$ reconstructions show a rise by $4 \mathrm{ppm}$ between $1000 \mathrm{AD}$ and $1100 \mathrm{AD}$ and a decrease by about 5 to $7 \mathrm{ppm}$ in the following 600 years. After $1750 \mathrm{AD}$, there is a steep increase towards modern values. The $\mathrm{CO}_{2}$ decrease coincides with a period of decreasing temperatures towards the LIA, suggesting that $\mathrm{CO}_{2}$ simply follows temperature. However, the relation is probably not that simple: for example, the cooling after the volcanic eruptions in the early 19th century, that drove the climate back into almost as cold condition as in the early 17th century does not show up strongly in the reconstructed $\mathrm{CO}_{2}$ records and the coincidence of the MWP with high $\mathrm{CO}_{2}$ levels around 1200 $\mathrm{AD}$ remains questionable. Therefore, although temperature changes certainly explain part of the observed $\mathrm{CO}_{2}$ variations, we cannot rule out that carbon-cycle variations related to mechanisms other than surface temperatures, such as redistributions in the oceanic/sediment pools, with timescales from century to millennia play a considerable role. In the simulations we start from a well-equilibrated carbon-cycle that may not exist in the real world.

The simulated sensitivity of the atmospheric $\mathrm{CO}_{2}$ concentration to temperature is not time invariant in the simulations. Estimates of $\gamma$ both from observations and model experiments provide an integrated quantification of climatecarbon cycle feedbacks, but the underlying processes are complex and are characterized by different time-scales and physical and biogeophysical mechanisms. We interpret the non-stationarity of $\gamma$ in our experiments as a response to different time-scales induced by the forcings with higher sensitivity for longer time-scales. Reorganisations in the slowly varying compartments ocean and carbon storage are apparently needed for the climate-carbon cycle feedback to fully develop.

The simulated climate and carbon-cycle response to variations in the external forcing is likely model-dependent. In particular, our model's sensitivity of global $\mathrm{CO}_{2}$ concentration in the atmosphere to $\mathrm{NH}$ temperature changes is on the lower end compared to the probabilistic estimate by Frank et al. (2010), in particular, for those estimates including the LIA $\mathrm{CO}_{2}$ drop. Frank et al. (2010) ruled out earlier findings with much greater numbers, but their estimate encompasses still a wide range (1.7-21.4 $\left.\mathrm{ppm} \mathrm{K}^{-1}\right)$. Model-based estimates of $\gamma$ reported in Frank et al. (2010) come from the short C4MIP simulations that were based on 1860-2100 climatechange experiments and are probably not representative for experiments with relatively weak and slowly-evolving external forcing, as has been demonstrated by the differences in our E1 and E2 experiments. Our analysis here is the first attempt to look at those long time scales and the diagnosed sensitivity of the feedback to the character of the forcing is encouraging, but must be confirmed by other model studies. Carbon-cycle model intercomparison exercises over longer periods are necessary to identify the model dependency of the interchange between the carbon pools.

The applied forcings, though state-of-the-art, come with a range of uncertainty. Recent estimates on the TSI increase from the Maunder Minimum to present have converged on a probable increase of about $1.3 \mathrm{Wm}^{-2}$, but the solar community still discusses how the findings from the last three solar cycles can be related to different states of the sun (see the recent review by Gray et al., 2010). Reconstructions of volcanic eruptions (Crowley et al., 2008; Gao et al., 2008) are based on ice-core sulphate records. They differ in their transfer function, mainly deduced from recent eruptions, to the 
optical properties and in the screening process for deciding what is an important eruption. These choices can lead to considerable differences in the radiative forcing for individual volcanic eruption (Schmidt et al., 2010).

Finally, the representation of the response to external forcing and the internal interaction between modes of variability (e.g. NAO, ENSO) depend on the model resolution and complexity. Owing to the long integration times we use a relatively coarse-resolution model. Although there is no doubt that inclusion of a dynamic stratosphere and UV variations on stratospheric ozone will alter the response to solar forcing (Mann et al., 2009; Spangehl et al., 2010), the details appear to be, again, model dependent (Palmer et al., 2004).

The experiments presented here are among the first ESM simulations that comply with the protocols of the Paleo Modelling Intercomparison Project Phase 3 (PMIP-3, http: //pmip3.lsce.ipsl.fr) and the upcoming Paleo Carbon Model Intercomparison Project (PCMIP). Analysing the role of external forcings and internal variability and the climate-carbon cycle feedbacks in a multi-model framework is a promising way to improve climate models to be used in future international assessments of climate change.

\section{Appendix A}

\section{Reconstruction data}

\section{A1 Temperature reconstruction data (Figs. 3a and 4)}

We used reconstruction data featured in Fig. 6.10 of the Intergovernmental Panel on Climate Change Fourth Assessment Report (Jansen et al., 2007). Data time series and the shaded representation of overlap (consensus) (main text Fig. 3a) were obtained from http://www.cru.uea.ac.uk/ datapages/ipccar4.htm. Acronyms used in Fig. 4 of the main text are identical with those in the IPCC AR4 (Jansen et al., 2007) Fig. 6.10: JBB1998 (Jones et al., 1998), MBH1999 (Mann et al., 1999), ECS2002 (Esper et al., 2002), B2000 (Briffa, 2000), MJ2003 (Mann and Jones, 2003), MSH2005 (Moberg et al., 2005), DWJ2006 (D'Arrigo et al., 2006), HCA2006 (Hegerl et al., 2006). In Table A1 we show the 30-year period with the warmest MWP (900-1300 AD) and coldest LIA (1550-1750 AD) temperatures. The left part of the table refers to the individual ensemble members and the right part of the table refers to the reconstructions with the same notation as in Fig. 4.

\section{A2 $\mathrm{CO}_{2}$ reconstructions (Fig. 6)}

The grey shading in Fig. 6 of the main text represents a compilation of atmospheric $\mathrm{CO}_{2}$ values together with their uncertainties into a "certainty" map by taking into account uncertainties in measured $\mathrm{CO}_{2}$ values and dating. It is based on data from the Antarctic ice cores Law Dome (MacFarling Meure et al., 2006a, b; Etheridge et al., 2006; Levchenko et al., 1996; Levchenko et al., 1997), EPICA Dome C (Siegenthaler et al., 2005; Monnin et al., 2004a, b), Dronning Maud Land (Siegenthaler et al., 2005a, b) and South Pole (Siegenthaler et al., 2005b). Each measurement value is associated with a Gaussian distribution over the combined space of $\mathrm{CO}_{2}$ values and time. The Gaussians are constructed such that they are centered at the particular measurement values, and the uncertainties in value and time are used as their standard deviations. Considering one data point, in this way, a value far off in $\mathrm{CO}_{2}$ value and/or time gets a smaller weight than a value close-by, and this reflects decreasing certainty with more distance. The certainty map is constructed from the individual Gaussians by summing up their contributions for a grid of points in the $\mathrm{CO}_{2}$ /time plane and normalizing along a line of constant time to 1 ; this normalization reflects the fact that $\mathrm{CO}_{2}$ must have a value at every time. In this way, points close to 1 (dark) are more certain than points close to zero (light).

\section{Appendix B}

\section{Estimation of trends in the forced simulations (Fig. 5)}

For a given length of the estimation period, the probability density function (pdf) derived from the linear trends represents the variability of the unforced system. The procedure is repeated for segment lengths between 10 and 100 years to derive upper and lower confidence limits. Black lines in Fig. B1 indicate the 5th and 95th percentile range. Thereafter, for specific times in the forced experiments, linear trends are compared with the confidence limits for the respective segment lengths. As an example, Fig. B1 displays trend estimates for forced experiments starting in the year $1400 \mathrm{AD}$. Trends (red and blue symbols) are calculated and displayed as a function of segment lengths in comparison with the range obtained from the control run pdfs (black lines). In these particular cases, trends between approximately 15 and 40 years (experiment E1_5), and 20 and 55 years (experiment E2_3) can be said to be significantly different from that expected on the basis of internal variability, with a random probability of occurrence of less then 0.05 . To construct Fig. 5 of the main text, this analysis was then carried out for starting dates throughout the millennium simulations with a 10 -year cadence $(800,810, \ldots, 1900)$ for all ensemble members.

\section{Appendix C}

\section{Co-variability of global mean temperature and $\mathrm{CO}_{2}$}

In constructing the scatter plot and regression lines (Fig. 8a of the main text), 3000 years of data from the control run and the first 900 years of the ensemble members of the forced simulations E1 and E2 were analyzed. Annually and globally 
Table B1. Timing of occurrence of the warmest MWP and coldest LIA 30-year climatological periods in (left) the simulations, and (right) the reconstructions (Jansen et al., 2007).

\begin{tabular}{crrrrr}
\hline Experiment & $\begin{array}{r}\text { Warmest } \\
\text { MWP period }\end{array}$ & $\begin{array}{r}\text { Coldest } \\
\text { LIA period }\end{array}$ & Reconstruction & $\begin{array}{r}\text { Warmest } \\
\text { MWP period }\end{array}$ & $\begin{array}{r}\text { Coldest } \\
\text { LIA period }\end{array}$ \\
\hline E1_1 & $1070-1099$ & $1670-1699$ & JBB1988 & $1030-1059$ & $1600-1629$ \\
E1_2 & $1100-1129$ & $1670-1699$ & MBH1999 & $1150-1169$ & $1660-1689$ \\
E1_3 & $1190-1219$ & $1580-1609$ & ECS2002 & $980-1009$ & $1600-1629$ \\
E1_4 & $1250-1279$ & $1640-1669$ & B2000 & $980-1009$ & $1670-1699$ \\
E1_5 & $1250-1279$ & $1640-1669$ & MJ2003 & $950-989$ & $1640-1679$ \\
E2_1 & $1220-1249$ & $1640-1669$ & MSH2005 & $1100-1129$ & $1580-1609$ \\
E2_2 & $1130-1159$ & $1670-1699$ & DWJ2006 & $980-1009$ & $1670-1699$ \\
E2_3 & $1190-1219$ & $1670-1699$ & HCA2006 & $950-979$ & $1640-1679$ \\
\hline
\end{tabular}

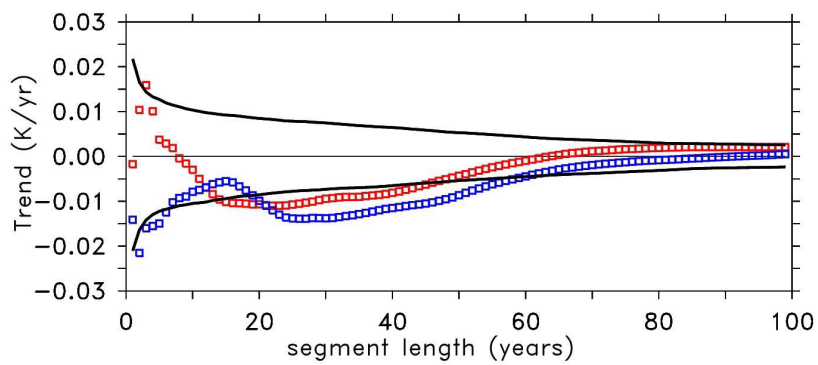

Fig. C1. Detection of significant trends in the time series for a particular start date (1400 AD): black lines indicate the 5th-95th percentile of the various trend lengths derived from the 3000-year control run. Coloured lines are trends from $\mathrm{NH}$ temperature time series from two forced runs (red: expt. E1_5 (weak solar), blue: expt. E2_3 (strong solar)).

averaged $\mathrm{CO}_{2}$ data and annually averaged Northern Hemisphere temperature data were analyzed in the frequency domain using 200 year windows with a 50 year overlap, resulting in 15 analysis windows for the forced simulations and 19 windows for the control simulations. The co-spectral data for the ensemble average of the 15 , respectively 19 , analysis periods was analyzed. Low pass filtering with a sharp spectral window was performed on detrended and tapered timeseries. The filter eliminated wave numbers larger than 3 . Tapering was performed over $5 \%$ of the time-series, but results were not sensitive to the length of the tapering period.

To construct the regressions the data were randomly sampled with a mean stride of $25 \pm 5$ years. The sample size was estimated following the methods of Zwiers and von Storch (1995). Regression slopes were calculated for different realizations. The realizations whose slopes matched the ensemble average were chosen for presentation in Fig. 8. Regression slopes varied by $\pm 0.07 \mathrm{ppm} \mathrm{K}^{-1}$ for the control and $0.06 \mathrm{ppm} \mathrm{K}^{-1}$ for the forced simulations.
Acknowledgements. This work has been carried out as part of the MPI-M Integrated Project Millennium and contributes to the Cluster of Excellence CLISAP at Hamburg University. Funding was provided by the ENIGMA project of the Max Planck Society (SJL), the DFG CAWSES Priority Program (NAK, LEV), the DFG Collaborative Research Center 574 (CT), and the WCU program of the Korean Ministry of Education, Science and Technology (SKS). The model simulations were carried out on the supercomputing system of the German Climate Computation Centre (DKRZ) in Hamburg. Data processing and storage were provided by the Model \& Data group at MPI-M. N. Krakauer, H. Wanner, P. Friedlingstein and one anonymous reviewer provided comments and recommendations that helped to improve the manuscript.

The service charges for this open access publication have been covered by the Max Planck Society.

Edited by: V. Rath

\section{References}

Ammann, C. M., Joos, F., Schimel, D. S., Otto-Bliesner, B. L., and Tomas, R. A.: Solar influence on climate during the past millennium: results from transient simulations with the NCAR climate system model, Proc. Natl. Acad. Sci. USA, 104, 37133718, doi:10.1073/pnas.0605064103, 2007.

Baehr, J., Keller, K., and Marotzke, J.: Detecting potential changes in the meridional overturning circulation at $26 \mathrm{~N}$ in the Atlantic, Climatic Change, 91, 11-27, 2008.

Balmaceda, L., Krivova, N. A., and Solanki, S. K.: Reconstruction of solar irradiance using the group sunspot number, Adv. Space Res., 40, 986-989, 2007.

Bard, E., Raisbeck G., Yiou, F., and Jouzel J.: Solar irradiance during the last 1200 years based on cosmogenic nuclides, Tellus, 52B, 985-992, 2000.

Boucher, O. and Pham, M.: History of sulfate aerosol radiative forcings, Geophys. Res. Lett., 29(9), 1308, doi:10.1029/2001GL014048, 2002.

Bradley, R. S., Hughes, M. K., and Diaz, H. F.: Climate in Medieval Time, Science, 302, 404-405, 2003. 
Bretagnon, P. and Francou, G.: Planetary theories in rectangular and spherical variables - VSOP 87 solutions, Astron. Astrophys., 202, 309-315, 1988.

Briffa, K.: Annual climate variability in the Holocene interpreting the message of ancient trees, Quat. Sci. Rev., 19, 87-105, 2000.

Brovkin, V., Lorenz, S. J., Jungclaus, J. H., Raddatz, T, Timmreck, C., Reick, C., Segschneider, J., and Six, K.: Sensitivity of a coupled climate-carbon cycle model to large volcanic eruptions during the last millennium, published online, Tellus, doi:10.111/j.1600-0889.2010.00471.x, 2010.

Camp, C. D. and Tung, K. K.: Surface warming by the solar cycle as revealed by the composite mean difference projection, Geophys. Res. Lett., 34, L14703, doi:10.1029/2007GL030207, 2007.

Cox, P. and Jones, C.: Illuminating the modern dance of climate and $\mathrm{CO}_{2}$, Science, 321, 1642-1644, 2008.

Crowley, T. J.: Causes of climate change over the last 1000 years, Science, 289, 270-277, 2000.

Crowley, T. J., Zielinski, G., Vinther, B., Udisti, R., Kreutz, K., Cole-Dai, J., and Castellano, J.: Volcanism and the Little Ice Age, PAGES Newsletter, 16, 22-23, 2008.

D'Arrigo, R., Wilson, R., and Jacoby, G.: On the long-term context for late twentieth century warming, J. Geophys. Res., 111, D03103, doi:10.1029/2005JD006352, 2006.

DeFries, R. S., Bounoua, L., and Collatz, G. J.: Combining satellite data and biogeochemical models to estimate global effects of human-induced land-cover changes on carbon emissions and primary productivity, Global Biogeochem. Cy., 13(3), 803-815, doi:10.1047/1999GB900037, 1999.

Esper, J., Cook, E. R., and Schweingruber, F. H.: Lowfrequency signals in long tree-ring chronologies for reconstructing past temperature variability, Science, 295, 2250-2253, doi:10.1126/science.1066208, 2002.

Etheridge, D., Steele, L., Langenfelds, R., Francey, R., Barnola, J., and Morgan, V.: Natural and anthropogenic changes in atmospheric $\mathrm{CO}_{2}$ over the last 1000 years from air in Antarctic ice and firn, J. Geophys. Res., 101, 4115-4128, 1996.

Fortuin, J. P. F. and Kelder, H.: An ozone climatology based on ozone sonde and satellite measurements, J. Geophys. Res., 103, 31709-31734, 1998.

Frank, D. C., Esper, J., Raible, C. C., Buentgen, U., Trouet, V., Stocker, B., and Joos, F.: Ensemble reconstruction constraints on the global carbon cycle sensitivity to climate, Nature, 463, 527530,2010 .

Friedlingstein, P., Bopp, L., Rayner, P., Betts, R., Jones, C., von Bloh, W., Brovkin, V., Cadule, P., Doney, S., Eby, M., Weaver, A. J., Fung, I., John, J., Joos, F., Strassmann, K., Kato, T., Kawamiya, M., and Yoshikawa, C.: Climate-carbon cycle feedback analysis: results from the C4MIP model intercomparison, J. Climate, 19, 3337-3353, 2006.

Fröhlicher, T. L., Joos, F., Plattner, G.-K., Steinacher, M., and Doney, S. C.: Natural variability and anthropogenic trends in oceanic oxygen in a coupled carbon cycle - climate model ensemble, Global Biogeochem. Cy., 23, GB1003, doi:10.1029/2008GB003316, 2009.

Fröhlicher, T. L. and Joos, F.: Reversible and irreversible impacts of greenhouse gas emissions in multi-century projections with the NCAR global coupled carbon cycle-climate model, Clim. Dynam., published online, doi:10.1007/s00382-009-0727-0, 2010.

Gao, C. C., Robock, A., and Ammann, C.: Volcanic forcing of climate over the past 1500 years: an improved ice corebased index for climate models, J. Geophys. Res., 113, D23111, doi:10.1029/2008JD010239, 2008.

Gerber, S., Joos, F., Brügger, P., Stocker, T. F., Mann, M. E., Sitch, S., and Scholze, M.: Constraining temperature variations over the last millennium by comparing simulated and observed atmospheric $\mathrm{CO}_{2}$, Clim. Dynam., 20, 281-299, 2003.

Goosse, H., Renssen, H., Timmermann, A., and Bradley, R. S.: Internal and forced climate variability during the last millennium: A model-data comparison using ensemble simulations, Quat. Sci. Rev., 24, 1345-1360, 2005.

Gonzalez-Rouco, F., Von Storch, H., and Zorita, E.: Deep soil temperature as proxy for surface air-temperature in a coupled model simulation of the last thousand years, Geophys. Res. Lett, 30(21), 2116, doi:10.1029/2003GL018264, 2003.

Gray, L. J., Beer, J., Geller, M., Haigh, J. D., Lockwood, M., Matthes, K., Cubasch, U., Fleitmann, D., Harrison, G., Hood, L., Luterbacher, J., Meehl, G. A., Shindell, D., Van Geel, B., and White, W.: Solar influence on climate, Rev. Geophys., published online, doi:10.1029/2009RG000282, 2010.

Houghton, R. A.: Balancing the global carbon budget, Annu. Rev. Earth Planet Sci., 35, 313-347, 2007.

Hegerl, G. C., Crowley, T. J., Hyde, W. T., and Frame, D. J.: Climate sensitivity constrained by temperature reconstructions over the past seven centuries, Nature, 440, 1029-1032, 2006.

Hibler, W. D.: A dynamic-thermodynamic sea-ice model, J. Phys. Oceanogr., 9, 815-846, 1979.

Jansen, E., Overpeck, J., Briffa, K., Duplessy, J.-C., Joos, F., Masson-Delmotte, V., Olago, D., Otto-Bliesner, B., Peltier, W., Rahmstorf, S., Ramesh, R., Raynaud, D., Rind, D., Solomina, O., Villalba, R., and Zhang, D.: Palaeoclimate, in: Climate change 2007: the physical science basis. Contribution of working group 1 to the Fourth Assessment Report of the Intergovernmental Panel on Climate Change, edited by: Solomon, S., Qin, D., Manning, M., Chen, Z., Marquis, M., Averyt, K., Tignor, M., and Miller, H., Cambridge University Press, Cambridge, 433497, 2007.

Jones, P. D., Briffa, K., Barnett, T., and Tett, S.: High-resolution paleoclimatic records for the last millennium: interpretation, integration and comparison with General Circulation Model controlrun experiments, Holocene, 8, 455-471, 1998.

Jones, C. D. and Cox, P. M.: Modeling the volcanic signal in the atmospheric CO2 record, Global Biogeochem. Cy., 15, 453-465, 2001.

Joos, F., Meyer, R., Bruno, M., and Leuenberger, M.: The variability in the carbon sinks for the last 1000 years, Geophys. Res. Lett., 10, 1437-1440, 1999.

Jungclaus, J. H., Botzet, M., Haak, H., Keenlyside, N., Luo, J.J., Latif, M., Marotzke, J., Mikolajewicz, U., and Roeckner, E.: Ocean circulation and tropical variability in the coupled model ECHAM5/MPI-OM, J. Climate, 19, 3952-3972, 2006.

Krivova, N. A., Balmaceda, L., and Solanki, S. K.: Reconstruction of solar total irradiance since 1700 from the surface magnetic flux, Aston. Astrophys. 467, 335-346, 2007.

Krivova, N. A. and Solanki, S. K.: Models of solar irradiance variations: Current status, J. Astrophys. Astr., 29, 151-158, 2008.

Lean, J. L. and Rind, D. H.: How natural and anthropogenic influences alter global and regional surface temperatures: 1889 to 2006, Geophys. Res. Lett., 35, L18701, 
doi:10.1029/2008GL034864, 2008.

Lefohn, A. S., Husar J. D., and Husar R. B.: Estimating historical anthropogenic global sulfur emission patterns for the period 1850-1990, Atmos. Env., 33, 3435-3444, 1999.

Le Quéré, C., Raupach, M. R., Canadell, J. G., Marland, G., et al.: Trends in the sources and sinks of carbon dioxide, Nature Geoscience, 2, 831-836, doi:10.1038/ngeo689, 2009.

Levchenko, V., Francey, R. J., Etheridge, D. M., Tuniz, C., Head, J., Morgan, I., Lawson, E., and Jacobsen, G.: The 14c "bomb spike" determines the age spread and age of $\mathrm{CO}_{2}$ in Law Dome firm and ice, Geophys. Res. Lett., 23, 3345-3348, 1996.

Levchenko, V., Etheridge, D. M., Francey, R. J., Trudinger, C., Tuniz, C., Lawson, E. M., Smith, A. M., Jacobsen, G. E., Hua, Q., Hotchkis, M. A. C., Fink, D., Morgan, V., and Head, J.: Measurements of the ${ }^{14} \mathrm{CO}_{2}$ bomb pulse in firn and ice at Law Dome, Antarctica. Nucl. Instrum. Methods, 123, 290-295, 1997.

MacFarling Meure, C. M., Etheridge, D., Trudinger, C., Steele, P., Langenfelds, R., van Ommen, T., Smith, A., and Elkins, J.: Law Dome $\mathrm{CO}_{2}, \mathrm{CH}_{4}$ and $\mathrm{N}_{2} \mathrm{O}$ ice core records extended to 2000 years BP, Geophys. Res. Lett., 33, L14810, doi:10.1029/2006GL026152, 2006.

Mann, M. E., Bradley, R. S., and Hughes, M. K.: Northern hemisphere temperatures during the past millennium: Inferences, uncertainties, and limitations, Geophys. Res. Lett., 26(6), 759-762, 1999.

Mann, M. E. and Jones, P. D.: Global surface temperatures over the past two millennia, Geophys. Res. Lett., 30(15), 1820, doi:10.1029/2003GL017814, 2003.

Mann, M. E., Zhang, Z., Hughes, M. K., Bradley, R. S., Miller, S. K., Rutherford, S., and Ni, F.: Proxy-based reconstructions of hemispheric and global surface temperature variations over the past two millennia, P. Natl. A. Sci., 105(36), 13252-13257, 2008.

Mann, M. E., Zhang, Z., Rutherford, S., Bradley, R. S., Hughes, M. K., Shindell, D., Ammann, C., Faluvegi, G., and Ni, F.: Global signatures and dynamical origins of the Little Ice Age and Medieval Climate Anomaly, Science, 326, 1256-1260, 2009.

Marland, G., Boden, T. A., and Andres, R. J.: 2003: Global, regional and national emissions, in: Trends: a compendium of data on global change. Carbon Dioxide Information Center, Oak Ridge National Laboratory, US Department of Energy, Oak Ridge, TN.

Marsland, S. J., Haak, H., Jungclaus, J. H., Latif, M., and Roeske, F.: The Max Planck Institute global ocean/sea ice model with orthogonal curvilinear coordinates, Ocean Modell., 5, 91-127, 2003

Moberg, A., Sonechkin, D., Holmgren, K., Datsenko, N., and Karén, W.: Highly variable Northern Hemisphere temperatures reconstructed from low- and high-resolution proxy data, Nature, 433, 613-617, 2005.

Monnin, E., Steig, E. J., Siegenthaler, U., Kawamura, K., Schwander, J., Stauffer, B., Stocker, T. F., Morse, D. C., Barnola, J.M., Bellier, B., Raynaud, D., and Fischer, H.: Evidence for substantial accumulation rate variability in Antarctica during the Holocene through synchronization of $\mathrm{CO}_{2}$ in the Taylor Dome, Dome C and DML ice cores, Earth Planet. Sc. Lett., 224, 45-54, 2004a.

Monnin, E., Steig, E. J., Siegenthaler, U., Kawamura, K., Schwander, J., Stauffer, B., Stocker, T. F., Morse, D. C., Barnola, J.-
M., Bellier, B., Raynaud, D., and Fischer, H.: EPICA Dome $\mathrm{C}$ ice core high resolution Holocene and transition $\mathrm{CO}_{2}$ data, Technical report, IGBP PAGES/World Data Center for Paleoclimatology, OAA/NGDC Paleoclimatology Program, Boulder CO, USA, 2004b.

Olofsson, J. and Hickler, T.: Effects of human land-use on the global carbon cycle during the last 6000 years, Vegetat. Hist. Archeobot., 17, 605-615, doi:10.1007/s00334-007-0126-6, 2008.

Palmer, M. A., Gray, L. J., Allen, M. R., and Noton, W. A.: Solar forcing of climate: model results, Adv. Space Res., 34, 343-348, 2004.

Pinto, J. P., Turco, R. P., and Toon, O. B.: Self-limiting physical and chemical effects in volcanic eruption clouds, J. Geophys. Res., 94(D8), 11165-11174, 1989.

Pongratz, J., Reick, C. H., Raddatz, T., and Claussen, M.: A Reconstruction of global agricultural areas and land cover for the last millennium, Global Biogeochem. Cy., 22, GB3018, doi:10.1029/2007GB003153, 2008.

Pongratz, J., Reick, C. H., Raddatz, T., and Claussen, M.: Effects of anthropogenic land cover change on the carbon cycle of the last millennium, Global Biogeochem. Cy., 23, GB4001, doi:10.1029/2009GB003488, 2009.

Ramankutty, N. and Foley, J.: Estimating historical changes in global land cover: Croplands from 1700 to 1992, Global Biogeochem. Cy., 13, 997-1027, 1999.

Raddatz, T. J., Reick, C. H., Knorr, W., Kattge, J., Roeckner, E., Schnur, R., Schnitzler, K. G., Wetzel, P., and Jungclaus, J.: Will the tropical land biosphere dominate the climate-carbon feedback during the twenty-first century?, Clim. Dynam., 29, 565574, 2007.

Reick, C. H., Raddatz, T., Pongratz, J., and Claussen, M.: Contribution of anthropogenic land cover emissions to preindustrial $\mathrm{CO}_{2}$, Tellus, B, published online, doi:10.1111/j.16000889.2010.00479.x, 2010.

Roeckner, E., Bäuml, G., Bonaventura, L., Brokopf, R., Esch, M., G., Hagemann, S., Kirchner, I., Kornblueh, L., Manzini, E., Rhodin, A., Schlese, U., Schulzweida, U., and Tompkins, A.: The atmospheric general circulation model ECHAM5. Part I: Model description., Tech. Rep. Rep. 349, 127 pp., Max Planck Institute for Meteorology, available from MPI for Meteorology, Bundesstr. 53, 20146 Hamburg, Germany, 2003.

Ruddiman, W. F.: The early anthropogenic hypothesis: challenges and responses, Rev. Geophys., 45, RG4001, doi:10.1029/2006RG000207, 2007.

Santer, B. D., Mikolajewicz, U., Brüggemann, W., Cubasch, U., Hasselmann, K., Höck, H., Maier-Reimer, E., and Wigley, T. M. L.: Ocean variability and its influence on the detectability of greenhouse warming signals, J. Geophys. Res., 100(C6), 10693 10725, 1995.

Sato, M., Hansen, J. E., McCormick, M. P., and Pollack, J. B.: Stratospheric aerosol optical depths, 1850-1990, J. Geophys. Res., 98(D12), 22987-22994, 1993.

Scheffer, M., Brovkin, V., and Cox, P. M.: Positive feedback between global warming and anthropogenic $\mathrm{CO}_{2}$ concentration inferred from past climate change, Geophys. Res. Lett., 33, L10702, doi:10.1029/2005GL025044, 2006.

Schmidt, G. A., Jungclaus, J. H., Ammann, C. M., Bard, E., Braconnot, P., Crowley, T. J., Delaygue, G., Joos, F., Krivova, N. A., 
Muscheler, R., Otto-Bliesner, B. L., Pongratz, J., Shindell, D. T., Solanki, S. K., Steinhilber, F., and Vieira, L. E. A.: Climate forcing reconstructions for use in PMIP simulations of the last millennium (v1.0), Geosci. Model Dev. Discuss., 3, 1549-1586, doi:10.5194/gmdd-3-1549-2010, 2010.

Servonnat, J., Yiou, J., Khodri, M., Swingedouw, D., and Denvil, S.: Influence of solar variability, $\mathrm{CO}_{2}$ and orbital forcing between 1000 and $1850 \mathrm{AD}$ in the IPSLCM4 model, Clim. Past, 6, 445460, doi:10.5194/cp-6-445-2010, 2010.

Shindell, D. T, Schmidt, G. A., Mann, M. E., Rind, D., and Waple, A.: Solar forcing of regional climate change during the Maunder Minimum, Science, 294, 2149-2152, doi:10.1126/science.1064363, 2001.

Siegenthaler, U., Monnin, E., Kawamura, K., Spahni, R., Schwander, J., Stauffer, B., Stocker, T. F., Barnola, J.-M., and Fischer, H.: Supporting evidence from the EPICA Dronning Maud Land ice core for atmospheric $\mathrm{CO}_{2}$ changes during the past millennium, Tellus, 57B, 51-57, 2005.

Siegenthaler, U.: EPICA Dronning Maud Land $\mathrm{CO}_{2}$ data for the last millennium, Data contribution series 2005-081, IGBP PAGES/World Data Center for Paleoclimatology, NOAA/NCDC Paleoclimatology Program, Boulder CO, USA, 2005.

Solanki, S. K., Usoskin, I. G., Kromer, B., Schuessler, M., and Beer, J.: Unusual activity of the Sun during recent decades compared to the previous 11000 years, Nature, 431, 1084-1087, 2004.

Spangehl, T., Cubasch, U., Raible, C. C., Schimanke, S., Körper, J., and Hofer, D.: Transient climate simulations from the Maunder Minimum to present day: Role of the stratosphere, J. Geophys. Res., 115, D00I10, doi:10.1029/2009JD012358, 2010.

Stendel, M., Morgensen, I. A., and Christensen, J. H.: Influence of various forcings on global climate in historical times using a coupled atmosphere-ocean general circulation model, Clim. Dynam., 26, 1-15, doi:10.1007/s00382-005-0041-4, 2006.

Steinhilber, F., Beer, J., and Fröhlich, C.: Total solar irradiance during the Holocene, Geophys. Res. Lett., 36, L19704, doi:10.1029/2009GL40142, 2009.

Tanre, D., Geleyn, J.-F., and Slingo, J. M.: First results of the introduction of an advanced aerosol-radiation interaction in the ECMWF low resolution global model, in: Aerosols and Their Climatic Effects, edited by: Gerber, H. and Deepak, A., Deepak Publishing, Hampton, VA, 133-177, 1984.

Tapping, K. F., Boteler, D., Charbonneau, P., Crouch, A., Manson, A., and Paquette, H.: Solar magnetic activity and total irradiance since the Maunder Minimum, Sol. Phys., 246, 309-326, 2007.
Tett, S. F. B., Betts, R., Crowley, T. J., Gregory, J., Johns, T. C., Jones, A., Osborn, T. J., Öström, E., Roberts, D. L., and Woodgate, M. J.: The impact of natural and anthropogenic forcings on climate and hydrology since 1550, Clim. Dynam., 28, 3-34, doi:10.1007/s00382-006-0165-1, 2007.

Timmreck, C., Lorenz, S. J., Crowley, T. J., Kinne, S., Raddatz, T., Thomas, M. A., and Jungclaus, J. H.: Limited temperature response to very large volcanic eruptions, Geophys. Res. Lett., 36, L21708, doi:10.1029/2009GL040083, 2009.

Trouet, V., Esper, J., Graham, N. E., Baker, A., Scourse, J. D., Frank, D. C.: Persistent positive North Atlantic Oscillation mode dominated the medieval climate anomaly, Science, 324, 78-80, 2009.

Trudinger, C. M., Enting, I. G., Rayner, P. J., and Francey, R. J. Kalman filter analysis of ice core data: 2 . Double deconvolution of $\mathrm{CO}_{2}$ and $\delta^{13} \mathrm{C}$ measurements, J. Geophys. Res., 107, 4423, doi:10.1029/2001JD001112, 2002.

Tung, K. K., Zhou, J., and Camp, C.: Constraining model transient climate response using independent observations of solar cycle forcing and response, Geophys. Res. Lett., 35, L17707, doi:10.1029/2008GL03240, 2008.

Usoskin, I. G., Solanki, S. K., and Kovaltsov, G. A.: Grand Minima of solar activity: new observational constraints, Astron. Astrophys., 471, 301-309, 2007.

Valcke, S., Caubel, D., and Terray, L.: OASIS Ocean Atmosphere Sea Ice Soil user's guide. CERFACS Tech Rep TR/CMGC/03/69, Toulouse, France, 85 pp., 2003.

Wang, Y.-M., Lean, J. L., and Sheeley, N. R., Jr.: Modeling the Sun's magnetic field and irradiance since 1713, Astrophys. J., 625, 522-538, 2005.

Wetherald, R. T. and Manabe, S.: Cloud feedback processes in a general circulation model, J. Atmos. Sci., 45, 1397-1415, 1998.

Wetzel, P., Maier-Reimer, E., Botzet, M., Jungclaus, J. H., Keenlyside, N., and Latif, M.: Effects of ocean biology on the penetrative radiation on a coupled climate model, J. Climate, 19, 39733987, 2006.

Woodwell, G. M., Mackenzie, F. T., Houghton, R. A., Apps, M., Gorham, E., and Davidson, E.: Biotic feedbacks in the warming of the Earth, Clim. Change, 40, 495-518, 1998.

Zwiers, F. W. and von Storch, H.: Taking serial correlation into account in tests of the mean, J. Climate, 8, 336-351, 1995. 